\title{
Refractory Chronic Lymphocytic Leukemia
}

National Cancer Institute

\section{Source}

National Cancer Institute. Refractory Chronic Lymphocytic Leukemia. NCI Thesaurus.

Code C7886.

Chronic lymphocytic leukemia that is resistant to treatment. 